Cravino, M.C. Justicia y política de hábitat en la Ciudad de Buenos Aires en desalojos de ocupaciones de suelo: Papa Francisco y Elefante Blanco. Derecho y Ciencias Sociales. Mayo- Octubre 2019 N $^{\circ} 21$. (Derecho, ciudad y propiedad) Pgs 104-129. ISNN 1852-2971. Instituto de Cultura Jurídica y Maestría en Sociología Jurídica. FCJ y S. UNLP

\title{
Justicia y política de hábitat en la Ciudad de Buenos Aires en desalojos de ocupaciones de suelo: Papa Francisco y Elefante Blanco
}

Justice and policy of habitat in Buenos Aires's City in evictions from land occupations: Papa Francisco y Elefante Blanco

\author{
María Cristina Cravino ${ }^{\bullet}$
}

\section{Resumen}

En el presente artículo nos proponemos analizar el Poder Judicial en situaciones de desalojo de ocupaciones de suelo urbano realizadas por sectores populares carentes de vivienda. Esto implica interrogarnos sobre los modos en que un ámbito del derecho problematiza los conflictos urbanos y los roles que ocupan los organismos judiciales en ellos, así como el contexto en el que actúan. Para ello indagaremos dos casos que sucedieron en terrenos de propiedad del Gobierno de la Ciudad de Buenos Aires, en porciones diferenciadas dentro de villas en proceso de re-urbanización. La gestión del desalojo de la Villa Papa Francisco (Villa Lugano, cercana al asentamiento de igual nombre) se realizó mediante una causa judicial penal y la del Elefante Blanco (Mataderos, cercana a la Villa 15) fue realizada de hecho por el gobierno local, a posteriori de la actuación del Fuero Contencioso Administrativo y Tributario en relación al saneamiento del lugar. Esta última expulsión fue avalada por dicho fuero en una modalidad gubernamental de arreglo familia por familia. Para el primer caso de desahucio se utilizó la violencia policial y para el segundo la coacción institucional formal e informal. Esto significó construcciones disimiles de legitimación y deslegitimación de los ocupantes y sus modos de desalojo.

Se presentan aquí los resultados parciales de un estudio cualitativo sobre judicialización de conflictos por el acceso al suelo urbano que recurre en diversos tipos de fuentes que son trianguladas: a) documentos emitidos en los tribunales; b) entrevistas a informantes claves dentro del Poder Judicial, dirigentes barriales y pobladores desalojados, miembros de ONGs y universidades, etc.; c) prensa escrita.

Palabras clave: Ciudad de Buenos Aires, villas, desalojos, Poder Judicial

\begin{abstract}
In this article we propose to analyse the Judicial Power in situations of eviction of urban land occupations carried out by popular sectors without housing.This involves asking ourselves about the ways in which the law problematizes urban conflicts and the sometimes contradictory roles that judicial bodies occupy.In turn, it requires incorporating the context of state intervention processes. To do this we will explore two cases that happened on land owned by the Government of the Buenos Aires's City, in differentiated portions within the slumsupgrading.The management of the eviction of the Papa Francisco slum was carried out through a criminal

\footnotetext{
- Antropóloga, Magister en Administración Pública y Doctora en Filosofía y Letras con orientación en antropología (UBA). Investigadora independiente (CONICET) con sede en la Universidad Nacional de Río Negro (CIETES). Coordinadora académica de la Maestría y doctorado en Estudios Urbanos de la Universidad Nacional de General Sarmiento y Coordinadora académica del Posdoctorado en Ciencias Humanas y Sociales de la Facultad de Filosofía y Letras (UBA). mccravino@gmail.com
}

Recibido: 1/3/2019. Publicable con correcciones: 5/9/2019. 
Cravino, M.C. Justicia y política de hábitat en la Ciudad de Buenos Aires en desalojos de ocupaciones de suelo: Papa Francisco y Elefante Blanco. Derecho y Ciencias Sociales. Mayo- Octubre 2019 N $^{\circ} 21$. (Derecho, ciudad y propiedad) Pgs 104-129. ISNN 1852-2971. Instituto de Cultura Jurídica y Maestría en Sociología Jurídica. FCJ y S. UNLP

court case and the Elefante Blanco was carried out in fact by the local government, after the performance of the Contentious Administrative Jurisdiction in relation to the sanitation of the place. This last expulsion was endorsed by said jurisdiction in a government modality of family arrangement by family.Police violence was used for the first case of eviction and formal and informal institutional coercion was used for the second.This meant dissimilar constructions of legitimization and no legitimization of the occupants and their modes of eviction. We present here the partial results of a qualitative study on the judicialization of conflicts over access to urban land, which resorts to different types of sources that are triangulated: a) documents issued in the courts; b) interviews with key informants within the Judicial Power, neighbourhood leaders and evicted residents, members of NGOs and universities, etc .; c) written press.

Keywords: Buenos Aires`s City, slums, evictions, Judicial Power 
Cravino, M.C. Justicia y política de hábitat en la Ciudad de Buenos Aires en desalojos de ocupaciones de suelo: Papa Francisco y Elefante Blanco. Derecho y Ciencias Sociales. Mayo- Octubre 2019 N $^{\circ} 21$. (Derecho, ciudad y propiedad) Pgs 104-129. ISNN 1852-2971. Instituto de Cultura Jurídica y Maestría en Sociología Jurídica. FCJ y S. UNLP

\section{Justicia y política de hábitat en la Ciudad de Buenos Aires en desalojos de ocupaciones de suelo: Papa Francisco y Elefante Blanco}

María Cristina Cravino

\section{Introducción}

Desde hace más de un siglo en las ciudades argentinas, surgieron las ocupaciones de suelo como una estrategia de los sectores de menores recursos para resolver la necesidad de obtener un lugar donde habitar. Cuando los pobladores de estos barrios populares lograron permanecer y autoconstruir allí sus viviendas dieron lugar a lo que se conoce como asentamientos populares (también adjetivados como informales, irregulares, ilegales, populares). En la Ciudad de Buenos Aires se conocen popularmente y académicamente como "villas". Durante algunos gobiernos, en particular en dictaduras militares, estos asentamientos fueron desalojados, pero en muchos otros se consolidaron urbana y socialmente y se implementaron en ellos diferentes programas de mejoramiento (Martínez, 2004; Cravino, 2008).

No obstante, en la última década, han crecido los desalojos de ocupaciones de suelo por parte de familias sin techo. Aun cuando la Constitución de la Ciudad de Buenos Aires en su artículo 31 garantiza la radicación como política local y recientemente, se sancionara la ley nacional 27.453 que estipula el freno a los desalojos en los asentamientos presentes en un registro oficial. Las causas penales por usurpación iniciadas por el Estado o por propietarios privados, además de múltiples procedimientos administrativos o de hecho, contribuyeron a la criminalización de los conflictos urbanos (Bertoni, 2010; CELS, 2017)

Nos interesa analizar en este artículo el rol de diferentes organismos del Poder Judicial en expulsiones de ocupaciones de suelo urbano. Para esto tomaremos dos casos (villa Papa Francisco y El Elefante Blanco) que sucedieron en terrenos de propiedad del Gobierno de la Ciudad de Buenos Aires, en porciones diferenciadas dentro de villas en proceso de reurbanización.

La gestión del desalojo de la Villa Papa Francisco (agosto 2014) se realizó mediante una causa judicial penal, mientras que la expulsión en el Elefante Blanco (2016 y 2017) fue realizada "de facto" por el gobierno local, en el marco de un proceso que comenzó en el Fuero Contencioso Administrativo y Tributario con el propósito de lograr el saneamiento del lugar. La expulsión fue avalada por dicho fuero en una modalidad gubernamental que consistió en una negociación familia por familia. 
Cravino, M.C. Justicia y política de hábitat en la Ciudad de Buenos Aires en desalojos de ocupaciones de suelo: Papa Francisco y Elefante Blanco. Derecho y Ciencias Sociales. Mayo- Octubre 2019 N $^{\circ} 21$. (Derecho, ciudad y propiedad) Pgs 104-129. ISNN 1852-2971. Instituto de Cultura Jurídica y Maestría en Sociología Jurídica. FCJ y S. UNLP

El tratamiento diferente de los casos nos obliga a problematizar el rol del derecho en los conflictos urbanos desencadenados por la ocupación de suelo protagonizada por los sectores populares, y los diferentes roles que cumplen los organismos judiciales, los que se definen, en buena medida, en interacción con el contexto político. Así, encontramos que para el primero de los casos se utilizó la violencia policial y para el segundo la coacción institucional formal e informal. Nuestra hipótesis es que este proceder diferenciado se explica por el objetivo disciplinador que primó en el primer caso, que a nuestro entender debe leerse como una continuidad del desalojo del Parque Indoamericano ocurrido en el año 2010 (Cravino, 2014), y la necesidad de un proceder más sigiloso en el segundo caso, ya que se encontraba enmarcado en una causa judicial -de un fuero distinto al penal- en la cual se discutían las condiciones urbano ambientales del asentamiento y estaban pendientes una serie de acciones a realizarse sobre el edifico. En cuanto a la metodología, se trata de un estudio cualitativo que recurre a diversos tipos de fuentes que son trianguladas: a) documentos emitidos en los tribunales; b) entrevistas a informantes claves dentro del Poder Judicial de la Ciudad de Buenos Aires, dirigentes barriales y pobladores desalojados, así como miembros de ONGs y universidades nacionales involucrados en los casos; c) complementariamente, se recurrió al análisis de las referencias de la prensa escrita. El artículo comienza con la presentación de cada uno de los casos, describiendo cómo se construyó el problema, los espacios pasibles de intervención y sus habitantes. Luego se analiza el Estado en sus diferentes facetas en relación a las definiciones de desalojo y sus variantes semánticas, para pasar, finalmente, a las reflexiones finales.

\section{Villa Papa Francisco: del rechazo inicial al desalojo violento}

En febrero de 2014 cientos de familias con necesidades habitacionales ocuparon un terreno contiguo a la Villa 20-Lugano. ${ }^{1}$ El predio estaba destinado a la urbanización de dicho asentamiento y hacía poco tiempo, gracias a una medida judicial, habían sido retirados de allí miles de automóviles abandonados, que correspondían a incautaciones de la Policía Federal y que contaminaron fuertemente el terreno. ${ }^{2}$ Los ocupantes, en su mayoría, eran inquilinos de las villas cercanas, en particular de la villa 20, que se encontraban en situación de no poder pagar

\footnotetext{
${ }^{1}$ Según datos del último Censo del año 2010, habitaban en la Villa 20 aproximadamente 21.000 personas en 4.377 viviendas.

${ }^{2}$ Hubieron sentencias del fuero Contencioso Administrativo y Tributario que obligaron a sanear el lugar, pero que fueron reiteradamente incumplidas por el Gobierno de la Ciudad. En el año 2008, la ley 2.724, de la legislatura declaró la emergencia ambiental y sanitaria y de infraestructura de este predio por un año y obligaba a la remediación del suelo del predio y la provisión de la infraestructura y de los servicios necesarios para la urbanización.
} 
Cravino, M.C. Justicia y política de hábitat en la Ciudad de Buenos Aires en desalojos de ocupaciones de suelo: Papa Francisco y Elefante Blanco. Derecho y Ciencias Sociales. Mayo- Octubre 2019 N $^{\circ} 21$. (Derecho, ciudad y propiedad) Pgs 104-129. ISNN 1852-2971. Instituto de Cultura Jurídica y Maestría en Sociología Jurídica. FCJ y S. UNLP

el alquiler o deseaban lograr un espacio propio en la ciudad para resolver sus necesidades habitacionales. Como todas las villas de la Ciudad de Buenos Aires se encontraba en fuerte crecimiento demográfico. ${ }^{3}$ Para los pobladores de la Villa 20 era "tierra de nadie” y, por lo tanto, espacio que suele ser ocupado para conformar una villa o en este caso ampliar la existente. Esto constituye una práctica social habitual de los sectores populares en su búsqueda de un lugar donde vivir (Cravino, 2006). También, para la percepción de quienes ocuparon ese espacio la extensión de dicho barrio, era un proceso que se venía dando a lo largo de los últimos años, donde muchas familias se asentaron sobre espacios de la vereda de la calle que delimitaba la villa o en pequeños lugares intersticiales. Al mismo tiempo, estos ocupantes portaban una visión de que esos terrenos vacíos no eran ajenos, sino por el contrario, eran "propios" de la villa 20 porque estaban expresamente destinados por la ley 1.770 a la urbanización de la misma. Esto era interpretado por los ocupantes como que ellos hacían lo que el Estado no había realizado y era su obligación: construir viviendas en ese predio. Así lo sostuvieron las personas entrevistadas a pocas semanas de conformarse la ocupación y en visitas siguientes.

Las personas permanecieron seis meses en el lugar hasta que se produjo el desalojo. Este período les permitió pasar de unas primeras construcciones extremadamente frágiles (de lona, chapa o cartón) a edificar viviendas con ladrillos (aunque precarias) y proveerse de tendidos provisorios de electricidad. Al mismo tiempo, comenzaron a organizarse territorialmente, lo que explica, en buena medida, su permanencia. La misma organización barrial consistía en lograr que se elija un representante por zona a fin de tomar decisiones de forma colectiva, y al mismo tiempo resolver cuestiones de la vida cotidiana en aquellas precarias condiciones. Ese proceso les facilitó a los habitantes pensarse y presentarse como una "villa". Para eso eligieron un nombre estratégico: Papa Francisco. Esto significaba una búsqueda de legitimidad social en un contexto donde en la esfera pública era visto como una toma de tierras conflictiva, en particular porque el Gobierno de la Ciudad de Buenos Aires en todo momento planteó su desalojo y calificó la ocupación de ilegal. Tener una identidad, les permitía a los habitantes (desde su perspectiva) una construcción simbólica del espacio que los alejaría del peligro de la expulsión porque significaría, a quien decida su desalojo, derribar un barrio popular con el nombre de un personaje argentino con legitimidad católica y proyección internacional. Como

\footnotetext{
${ }^{3}$ Como lo indican los datos del INDEC que arrojan un crecimiento de más del $50 \%$ en el último período intercensal. Esa población accede al espacio habitacional fundamentalmente a través del alquiler (Cravino, 2006), forma que según estimaciones actuales alcanza a una cifra superior al 30\% de la población.
} 
Cravino, M.C. Justicia y política de hábitat en la Ciudad de Buenos Aires en desalojos de ocupaciones de suelo: Papa Francisco y Elefante Blanco. Derecho y Ciencias Sociales. Mayo- Octubre 2019 N $^{\circ} 21$. (Derecho, ciudad y propiedad) Pgs 104-129. ISNN 1852-2971. Instituto de Cultura Jurídica y Maestría en Sociología Jurídica. FCJ y S. UNLP

plantea Munck (1995) la corriente europea de los movimientos sociales enfatiza la dimensión identitaria para cohesionar al grupo y ese sería otro de los efectos de presentarse como "barrio" y con el nombre "Papa Francisco". Implicaba mostrarse como un espacio consolidado y establecido, que lo hacía más difícil ser objeto de desalojo.

Veamos ahora el tratamiento de la ocupación en los tribunales. La primera agencia judicial que acudió al predio fue el Ministerio Público Fiscal, que el mismo día de la toma del predio inició un proceso por usurpación. ${ }^{4}$ Un juez del Fuero Penal ${ }^{5}$ dio lugar a lo solicitado por aquel organismo, con los mismos argumentos planteados que se centraban en la necesidad del desalojo para restituir el inmueble. De este modo, se decidió el allanamiento, desocupación y restitución del inmueble (como es habitual en estos casos y lo prevé el Código Penal). Además, se alegaba urgencia, aludiendo a las condiciones del lugar (contaminación del suelo y plagas) y agregando un elemento que fuera esgrimido como cuestión central para definir la suerte del conflicto: inseguridad en las cercanías. Por otra parte, se aducía la imposibilidad de dialogar con los pobladores -situación que según éstos últimos ni siquiera se intentó- y se pasó directamente a la solicitud de expulsión de ellos del lugar sin más condiciones.

El Juzgado Penal encomendó a la Policía Metropolitana el desalojo, pero solicitó tomar en cuenta la Observación General $N^{\circ} 7$ de la Comisión del Pacto Internacional de Derechos Económicos, Sociales y Culturales. Esto significaba el pedido de asistencia social al gobierno de la Ciudad de Buenos Aires. Coincidentemente con esas recomendaciones, y como se utilizó en muchos otros casos de desalojos en la Ciudad de Buenos Aires (de ocupaciones de suelo o de edificios), se requirió la presencia de distintas áreas dependientes del gobierno de la Ciudad y de otros organismos, como: 1) la Dirección General de Atención Inmediata a través del Programa Buenos Aires Presente, destinado a personas en situación de calle; 2 ) ofrecimiento de las instancias de atención social y derivación de los distintos programas sociales locales; 3 ) la Dirección General de Guardia de Auxilio y Emergencias para realizar tareas pertinentes en relación a los riesgos habituales en caso de desalojo; 4) el sistema médico de emergencia; 5) el Consejo de los Derechos de Niñas, Niños y Adolescentes, a efectos de asistir a niños solos o sin adulto responsable; 6) la Dirección de Minoría y sus Garantías, a fin de garantizar que se cumplan los estándares básicos de derechos y garantías a las minorías y 7) el Ente de Higiene

\footnotetext{
${ }^{4}$ Causa penal $\mathrm{N}^{\circ} 2.287 / 14$.

${ }^{5}$ Juzgado $N^{\circ} 14$, Juez Dr. Gabriel Eduardo Vega.
} 
Cravino, M.C. Justicia y política de hábitat en la Ciudad de Buenos Aires en desalojos de ocupaciones de suelo: Papa Francisco y Elefante Blanco. Derecho y Ciencias Sociales. Mayo- Octubre 2019 N $^{\circ} 21$. (Derecho, ciudad y propiedad) Pgs 104-129. ISNN 1852-2971. Instituto de Cultura Jurídica y Maestría en Sociología Jurídica. FCJ y S. UNLP

Urbana, para que limpiara el espacio una vez concluido el procedimiento. ${ }^{6}$ Es decir, en el pedido, se solicitaba que se cumpliera con la asistencia social y, en particular, los estándares internacionales de resguardo de derechos de niños y minorías, pero también la limpieza del lugar para que no queden rastros de la ocupación y todo volviera, supuestamente, a ser como antes. Frente a esta decisión, intervino la Defensoría Oficial, ${ }^{7}$ apelando la medida y alegando la no urgencia del desalojo. Estos pedidos no prosperaron. Es decir, el juzgado respondió a la solicitud del Poder Ejecutivo local, primando una mirada penalista de las ocupaciones y no derivando el caso a otras esferas judiciales que pudieran contemplar el derecho a la vivienda o a espacios de negociación política. Es decir, se contraponía el derecho a la propiedad (que implicaba tipificar el caso como usurpación) frente al derecho a la vivienda. Como se sostuvo en otros trabajos (Cravino, 2016) el Poder Judicial reproducía la centralidad de la propiedad privada como una institución central en la sociedad.

Debido a desarreglos entre el gobierno nacional, del que dependía la Policía Federal, ${ }^{8}$ y el gobierno local el desalojo se fue posponiendo. De hecho, ante la continuidad de la ocupación y como sucedía en casos similares se buscó conocer la cantidad de personas involucradas y sus características y para esto en junio se realizó un censo.

La práctica de los censos, como mecanismo para determinar los futuros beneficiarios de programas habitacionales, ha sido indagada por diferentes autores. Como el trabajo de Olejarczyk (2013), que analiza la construcción de sujetos políticos a partir de la utilización de los censos en los programas federales de construcción de viviendas. Moreno y Manzano (2011) focalizan en la relación entre funcionarios estatales y miembros de organizaciones socio-

\footnotetext{
${ }^{6}$ En la parte dispositiva la orden de desalojo indica que teniendo en cuenta los contenidos de la observación general $\mathrm{N}^{\circ} 7$ ya citada, la autoridad que dirigirá el procedimiento, deberá realizar y/o tener en cuenta, distintos puntos, entre ellos: 1) que la medida sea realizada en el horario diurno ya establecido y en condiciones meteorológicas normales; 2) que la cantidad de personal de las fuerzas de seguridad que lleven a cabo el desalojo sea proporcional a la cantidad de ocupantes del predio, sin perjuicio de los que sean necesarios para asegurar que el procedimiento se lleve a cabo pacíficamente, impidiendo el acceso de terceras personas a la zona; 3 ) que se identifique en forma previa a todos los funcionarios policiales que participen en el operativo y 4) que se registre en soporte fílmico el modo de ejecución del desalojo.

${ }^{7}$ El Ministerio Público de la Defensa (MPD) es un organismo del Poder Judicial de la Ciudad Autónoma de Buenos Aires que garantiza el acceso universal y gratuito a la Justicia. Tiene su origen en el artículo 124 de la Constitución de la Ciudad, que crea el Ministerio Público, integrado por un Defensor, un Fiscal y un Asesor Tutelar. El objetivo institucional es velar para que el sistema de administración de Justicia cumpla y promueva las garantías constitucionales y el derecho al libre acceso a la Justicia. Tiene como función garantizar el acceso universal y gratuito a la Justicia y la debida defensa en juicio, sobre todo a aquellas personas en situación de vulnerabilidad o exclusión social. Disponible en: https://www.buenosaires.gob.ar/guiajuridicagratuita/ministeriopublico-de-la-defensa, consultado el 15 de enero de 2019.

${ }^{8}$ El gobierno porteño aducía que la Policía Metropolitana no tenía capacidad para hacer la tarea y pedía que la hiciera la Policía Federal.
} 
Cravino, M.C. Justicia y política de hábitat en la Ciudad de Buenos Aires en desalojos de ocupaciones de suelo: Papa Francisco y Elefante Blanco. Derecho y Ciencias Sociales. Mayo- Octubre 2019 N $^{\circ} 21$. (Derecho, ciudad y propiedad) Pgs 104-129. ISNN 1852-2971. Instituto de Cultura Jurídica y Maestría en Sociología Jurídica. FCJ y S. UNLP

políticas barriales, y en cómo la producción de registros censales permitía a estos últimos fundamentar y habilitar demandas ante diferentes áreas y organismos estatales. Según estos autores, implica hablar en el lenguaje del Estado y generar espacios de negociación con funcionarios gubernamentales. Al tratarse de un modo de hacer estatal, los datos censales se inscriben en nociones legitimadoras que se ponen en juego en procesos de movilización colectiva. Eso puede ser interpretado como el reconocimiento de la existencia de la ocupación, situación que como veremos a continuación no sucedió en este caso.

En un trabajo previo (Cravino y González Carvajal, 2012), nos centramos en los criterios de merecimiento de viviendas en procesos de re-urbanización de villas en el Conurbano Bonaerense. En esa oportunidad, pudimos constatar que contar con un certificado de censo o constar en los mismos era un elemento sumamente importante, tanto para los funcionarios gubernamentales como para los vecinos, como criterio de merecimiento del acceso a una vivienda. Para los primeros implicaba comprobar que los beneficiarios habían acumulado la antigüedad necesaria (requisito exigido por diversos programas sociales), y cumplían los requisitos burocráticos para acceder a los programas. Para los vecinos significaba el reconocimiento por ser antiguos pobladores y, por lo tanto, quienes habían participado de la construcción del barrio.

Por su parte, los ocupantes entrevistados en Papa Francisco hacían referencia a la importancia del censo, inclusive para despejar los rumores de quiénes eran los que ocupaban, ya que se afirmaba en los medios de comunicación que eran "de otros barrios", "oportunistas", etc. Ellos creían que ese procedimiento era en respuesta a las presiones que recibía el gobierno local por parte de políticos de la oposición y de organismos de derechos humanos e, inclusive, del Papa de la Iglesia Católica.

El 20 de agosto de 2014 murió una joven en un asalto a pocas cuadras de la villa Papa Francisco, lo que derivó en una nueva tematización de la ocupación y comenzó a circular en la opinión pública, gracias a la voz del Gobierno de la Ciudad de Buenos Aires, la información de que allí habitaban "narcotraficantes”. Según Trufó et al.

Para los vecinos y referentes entrevistados, la muerte de la joven fue producto de una maniobra premeditada a cargo de "las patotas políticas" que lograron desestabilizar la toma para obtener el apoyo de vecinos lindantes con el objetivo de iniciar el desalojo. $(2017: 155)$ 
Cravino, M.C. Justicia y política de hábitat en la Ciudad de Buenos Aires en desalojos de ocupaciones de suelo: Papa Francisco y Elefante Blanco. Derecho y Ciencias Sociales. Mayo- Octubre 2019 N $^{\circ} 21$. (Derecho, ciudad y propiedad) Pgs 104-129. ISNN 1852-2971. Instituto de Cultura Jurídica y Maestría en Sociología Jurídica. FCJ y S. UNLP

Estos autores plantean que existe un patrón en diferentes situaciones de ocupaciones del Área Metropolitana de Buenos Aires donde las bandas delictivas buscan instalarse, pero que también generan hechos que legitiman los desalojos. Desde el discurso del Gobierno de la Ciudad de Buenos Aires se aludía al lugar como "tierra de nadie con sello narco". Merece resaltarse que el Estado local utilizó también la categoría nativa "tierra de nadie", pero en este caso se agregaba una connotación negativa y se la asociaba a un territorio con presencia de actividades delictivas, lo que generaba un reconocimiento implícito de la falta de control estatal en el mismo.

El desalojo se hizo mediante engaños a los ocupantes, ya que se anunció como un allanamiento en búsqueda de los culpables del asesinato, modalidad que es típica ante este tipo de hechos cuando se trata de asentamientos populares. El mismo se llevó a cabo en la madrugada del 23 de agosto de 2014, momento en el cual estaban asentadas 400 familias aproximadamente. ${ }^{9}$ Fue realizado con violencia y se destruyeron muchas de las pertenencias de las familias. Ese día personal judicial, policial y del gobierno local se presentaron en el predio, sin notificación o anuncio previo respecto de la fecha efectiva del desalojo. ${ }^{10}$ Esto violaba lo solicitado originalmente en relación a la Observación 7 del Pacto de DESC, en cuanto a que se debe proceder en horarios diurnos, ya que en esa época del año, a las cinco de la madrugada no hay luz solar. La orden provenía del juzgado penal interviniente. Ante estos hechos, la vicejefa de Gobierno de la Ciudad de Buenos afirmó que "no permitiremos que las mafias se aprovechen de la necesidad de otros". ${ }^{11}$ Se repetía una vez más la idea "tierra de nadie con sello narco". ${ }^{12}$

Como era de prever en esta situación, para los ocupantes fue imposible embalar todas sus pertenencias porque estaban asustados y no tenían dónde colocarlas para llevarlas al transporte, más aún en un contexto de represión. Inmediatamente y sin verificar que todo se hubiera llevado, las topadoras arrasaron con el lugar, destruyendo las casas y casillas, con lo que hubiera quedado adentro. Participaron un importante número de efectivos policiales $(2.000$ según el diario La Nación del 24 de agosto de 2014 o 1.000 de acuerdo al diario Perfil de la misma fecha). Hubo también legisladores heridos, los que se habían acercado rápidamente al

\footnotetext{
${ }^{9}$ Hay discrepancias respecto del número real de familias. Mientras que el censo de junio indicaba 700 familias, el Ministro de Seguridad afirmó que se desalojaron 500 personas.

10 "El operativo se ideó en reserva, lo que ayudó al éxito. El predio va a quedar en custodia y la Jueza decidirá si eso lo harán fuerzas de la Gendarmería o la Metropolitana", sostuvo Martín Ocampo, Fiscal General de la Ciudad (Clarín, Buenos Aires, 23 de agosto de 2014).

${ }^{11}$ La Nación, Buenos Aires, 24 de agosto de 2014. Disponible en: https://www.lanacion.com.ar/1721329-despuesde-un-homicidio-ordenaron-el-desalojo-de-la-villa-papa-francisco, consultado el 15 de enero de 2019.

12 Clarín, Buenos Aires, 23 de agosto de 2014. Disponible en: https://www.clarin.com/policiales/Intentandesalojar-usurpado-Villa-Lugano_0_Hyl9KNq5P7x.html, consultado el 10 de enero de 2019.
} 
Cravino, M.C. Justicia y política de hábitat en la Ciudad de Buenos Aires en desalojos de ocupaciones de suelo: Papa Francisco y Elefante Blanco. Derecho y Ciencias Sociales. Mayo- Octubre 2019 N $^{\circ} 21$. (Derecho, ciudad y propiedad) Pgs 104-129. ISNN 1852-2971. Instituto de Cultura Jurídica y Maestría en Sociología Jurídica. FCJ y S. UNLP

lugar al enterarse de los hechos. Los medios de comunicación vincularon el asesinato ocurrido pocos días antes cerca del predio con el desalojo (como en la nota del diario La Nación citada en la nota 11) y daban cuenta de la resistencia de las personas a irse del lugar. Se informaron ocho detenidos y seis heridos. ${ }^{13}$ Un relato de la prensa indicaba lo que podría ser una buena síntesis de lo ocurrido: "Lágrimas e indignación. Con angustia, los ocupantes resistieron la llovizna de la mañana y el intenso calor de la tarde" (Clarín, Buenos Aires, 24 de agosto de 2014) y continuaba: "De acá no nos vamos", (...), repetían los desalojados, entre quienes se encontraban familias numerosas, mujeres embarazas, niños y discapacitados, que también fueron agredidos durante el operativo".

Ante la situación alrededor de 50 familias decidieron acampar al lado del lugar desalojado. Allí permanecieron muchos meses esperando una respuesta. Algunos de ellos presentaron un recurso de amparo pidiendo una solución habitacional entre otras cosas, el que no prosperó. En el pedido, se hacía referencia a que muchos habitantes del asentamiento desalojado fueron ubicados en paradores (Parque Chacabuco, Parque Avellaneda y el parador Pereyra, entre otros) y que éstos eran utilizados para albergar a personas en situación de calle, en particular en días de mucho frío. Más grave aún, informaban que "las familias en estos paradores estaban denunciando que faltan alimentos, agua, se encuentran hacinados sin cama y durmiendo en los pasillos". Además: "En muchos casos las familias fueron separadas y a otras les dicen que vayan a alquilar a otras villas" o les están ofreciendo un subsidio habitacional por unos meses (Pedido de medida Cautelar firmado por Jonatan Baldiviezo). ${ }^{14}$

Apelar a los tribunales en conflictos de derechos sociales tiene lugar creciente, en particular en la Ciudad de Buenos Aires (Delamata, 2014), pero, no obstante, no siempre se tiene eco en ellos. En este caso, aquellos pedidos no prosperaron, pero luego del desalojo intervino el Fuero Contencioso Administrativo y Tributario de la Ciudad. ${ }^{15}$ Este tribunal, a pesar de que no hizo lugar a la cautelar solicitada por los ocupantes del predio desalojado, aceptó la solicitud en relación a la urbanización de la villa 20 que venía siendo postergada. Un argumento que utilizó la jueza para el rechazo fue que incurrir en la toma de tierra no otorgaba derechos a las familias. Como solución, la magistrada recomendó que cada una de las familias presentase individualmente ante la secretaría de su juzgado la solicitud de subsidios para llevar adelante la

13 Perfil, Buenos Aires, 24 de agosto de 2014. Disponible en: https://www.perfil.com/noticias/sociedad/desalojaron-con-incidentes-el-predio-tomado-en-villa-lugano-201408240037.phtml, consultado el 10 de febrero de 2019.

${ }^{14}$ La Alameda, 9 de noviembre de 2014. Disponible en: https://laalameda.wordpress.com/2014/09/11/cautelarpor-viviendas-transitorias/, consultado el 20 de diciembre de 2018.

${ }_{15}$ Juzgado $N^{\circ} 4$, jueza Elena Liberatori. 
Cravino, M.C. Justicia y política de hábitat en la Ciudad de Buenos Aires en desalojos de ocupaciones de suelo: Papa Francisco y Elefante Blanco. Derecho y Ciencias Sociales. Mayo- Octubre 2019 N $^{\circ} 21$. (Derecho, ciudad y propiedad) Pgs 104-129. ISNN 1852-2971. Instituto de Cultura Jurídica y Maestría en Sociología Jurídica. FCJ y S. UNLP

evaluación de cada requerimiento, como cualquier persona en situación de calle. En cuanto a la Villa 20 ordenó al gobierno porteño urbanizarla "antes del 10 de diciembre de 2015" y dispuso que se reasigne las partidas del presupuesto del 2014 para comenzar los trabajos en lo que restaba de ese año, incluyendo la construcción de viviendas contempladas en la ley 1.770.

El discurso de los fallos permite en muchos casos mostrar la apreciación de los jueces sobre la realidad social. En este caso, incluyó en los considerandos una carta del Papa Francisco en la que se solidarizaba con los desalojados y se lamentaba por las escenas de la remoción que le recordaron "imágenes de la Franja de Gaza". ${ }^{16}$ Su intervención ex post, le negaba, entonces, el carácter de villa a las viviendas construidas en el predio y lo consideraba, por el contrario, una ocupación provisoria. A su vez, una vez producido el desahucio, como se indicó, igualaba a las personas que lo sufrieron con las que se encuentran en situación de calle. Por otro lado, consolidaba la idea de un pacto social de amnistía en relación a las villas anteriores y, en paralelo, una prohibición implícita de nuevas ocupaciones. Todo esto más allá de lo que indica la Constitución porteña, ya que esta no establece una antigüedad determinada para ser incorporada a procesos de radicación. Esta respuesta de la jueza y el inicio temprano de las causas penales contribuyeron también a la desmovilización social. A esto se suma que los medios de comunicación lograron instalar la ocupación como un "hecho de mafias" del narcotráfico.

De este modo, dentro del Poder Judicial, se reafirmó (junto al Parque Indoamericano) una ruptura del ciclo del activismo judicial que tenía como protagonista al Fuero Contencioso Administrativo y Tributario de la Ciudad de Buenos Aires, y que buscaba garantizar los derechos sociales a los habitantes de las villas (Delamata, 2014; Cravino, 2016). Ya no sólo no buscaron frenar el desalojo, sino por el contrario lo legitimaron. El argumento de peligro ambiental fue esgrimido por la jueza de este fuero para no hacer lugar al pedido de la defensa. Apelar al ambiente es un elemento de fuerte legitimidad social (Azuela, 2014; Carman, 2006; Cravino y Fainstein, 2017), que lo coloca por delante de las necesidades habitacionales. Así se llega a la situación paradójica, que en nombre de la calidad de vida de los ocupantes el Poder Judicial los desalojaba sin garantizar una vivienda alternativa, mientras para los pobladores el sufrimiento ambiental (Auyero y Swistun, 2007) pasaba a segundo plano en relación al padecimiento que significaba la falta de un techo.

16 Disponible en: http://www.panoramaciudad.com.ar/2014/08/la-justicia-ordeno-al-gobierno-porteno.html, consultado el 5 de febrero de 2019. 
Cravino, M.C. Justicia y política de hábitat en la Ciudad de Buenos Aires en desalojos de ocupaciones de suelo: Papa Francisco y Elefante Blanco. Derecho y Ciencias Sociales. Mayo- Octubre 2019 N $^{\circ} 21$. (Derecho, ciudad y propiedad) Pgs 104-129. ISNN 1852-2971. Instituto de Cultura Jurídica y Maestría en Sociología Jurídica. FCJ y S. UNLP

Mientras tanto, el Poder Ejecutivo local intentaba mitigar el impacto político del desahucio ofreciendo algunas formas de albergue provisorios como a las personas en situación de calle. Esto lo diferencia de la ocupación del Parque Indoamericano, donde esta ayuda no se proveyó y sólo surgió una promesa a futuro de programas de viviendas de interés social para la ciudad, donde algunos de los receptores podían ser los ocupantes (Cravino, 2014) y donde se comprometió también el gobierno nacional. ${ }^{17}$ Esa respuesta nunca llegó y se buscó reforzar los efectos pedagógicos que implicaban desalentar nuevas ocupaciones. Paradójicamente, esa expulsión violenta puede pensarse como el origen de la conformación de la villa Papa Francisco, ya que muchos de los ocupantes habían participado de aquella toma de tierra.

El Fuero Penal investigó los hechos ocurridos en 2014 en relación a la ocupación. A pesar de ser un conflicto socio urbano, muchos de los dispositivos utilizados fueron los propios de otro tipo de causas penales, como el narcotráfico (ejemplo: escuchas telefónicas). De la investigación llevada a cabo por el fiscal, se concluyó que la usurpación del predio había sido planificada por un grupo de personas. El fiscal solicitó llevar a juicio a todos los imputados en la causa. La jueza ${ }^{18}$ resolvió en septiembre de 2015, la nulidad de las pericias informáticas y dispuso el sobreseimiento de todos los imputados en la causa. Sin embargo, el fiscal apeló dicha resolución y en febrero de 2016, la Sala III de la Cámara de Apelaciones revocó la decisión, ordenando continuar con la investigación del fiscal y apartando a la jueza de la causa. La condena dictada por el nuevo juez ${ }^{19}$ no sólo significó una pena de prisión efectiva para Carlos Jiménez ${ }^{20}$, sino que ratificó la hipótesis que sostuvo el fiscal desde el principio de la investigación respecto a que se trató de una toma previamente organizada, planificada y llevada a cabo conforme a un plan de acción. El acusado fue a prisión, teniendo en cuenta que presentaba antecedentes de delitos penales.

Los ocupantes entrevistados desmintieron la idea que dirigentes barriales $\mathrm{u}$ otras personas los impulsaron a tomar tierra, sino por el contrario escucharon el rumor de que esa tierra era del gobierno y no de la policía y hacía tiempo que se decía que alguien la iba a ocupar. En ese contexto los entrevistados estaban atentos a la posibilidad de tener un lugar para construir una vivienda y dejar de pagar alquiler. No obstante, algunos no descartaban un juego de presiones de algunos dirigentes, aun cuando fueran oficialistas en relación al Gobierno de la Ciudad de

\footnotetext{
${ }^{17}$ El gobierno nacional se había comprometido a poner un monto similar de dinero al que pondría el gobierno local.

${ }^{18}$ María Gabriela López Iñiguez.

${ }^{19}$ Rodolfo Ariza Clerici, a cargo del Juzgado Penal, Contravencional y de Faltas $\mathrm{N}^{\circ} 1$.

${ }^{20}$ Contaba con una condena previa por la portación de un arma de fuego sin permiso (artículo 189 del Código Penal). En dicha causa se encontraba prófugo de la justicia desde hacía un año.
} 
Cravino, M.C. Justicia y política de hábitat en la Ciudad de Buenos Aires en desalojos de ocupaciones de suelo: Papa Francisco y Elefante Blanco. Derecho y Ciencias Sociales. Mayo- Octubre 2019 N $^{\circ} 21$. (Derecho, ciudad y propiedad) Pgs 104-129. ISNN 1852-2971. Instituto de Cultura Jurídica y Maestría en Sociología Jurídica. FCJ y S. UNLP

Buenos Aires. También hicieron referencias a que hubo ventas de algunos lotes y presiones para su cobro. Como se señaló para el caso del Indoamericano, la organización social en la teoría penal, se mira sólo con el tamiz del delito y no como un hecho social (Cravino, 2016). Es decir, la ocupación del predio contiguo a la Villa 20, en terrenos correspondientes a su urbanización quedó enmarcada en hechos delictivos, despojándose de toda conflictividad social.

\section{EI Elefante blanco: desalojo familia por familia y legitimado por la justicia}

El desalojo del edificio llamado "El Elefante Blanco", se produjo entre 2016 y 2017. Se trataba de la ocupación de una estructura de hormigón vacía que había sido destinada a un hospital que no se concretó. Luego adoptó el nombre de Centro de salud Mataderos (Ferreira, 2016) y eran tres bloques de 12 pisos cada uno. Este predio se ubicaba contiguo a la villa 15 de Mataderos. A diferencia del primer caso, esta ocupación fue gradual en el tiempo. Este lugar comenzó a estar habitado en la década de 1980, cuando aún se encontraba en el gobierno nacional la última dictadura militar, que había generado que gran cantidad de personas quedaran sin vivienda, ya sea por desalojos de villas, como liberalización del precio de los alquileres y otras medidas (Oszlak, 1991). Luego, también se fueron instalando familias en sus alrededores, los que estaban libres, y habían sido contemplados como lugares para estacionamientos y otros destinos. Su consolidación como espacio habitacional se dio en la década de 1990, bajo un contexto de gobierno neoliberal (Ferreira, 2016). Por ser una estructura vacía, los pobladores se vieron obligados a construir viviendas dentro, dando como resultado una precariedad aún mayor a la que habitualmente se encuentra en muchos de los asentamientos informales de la Ciudad de Buenos Aires. Esto se debe a que ni siquiera contaba con caños cloacales clandestinos o había zonas vacías riesgosas, particularmente para niños.

El conflicto tuvo dos momentos: el primero a partir de un reclamo de los habitantes sobre las condiciones urbano ambientales del edifico, el que provocó la solicitud de un amparo colectivo por parte del Ministerio Público de la Defensa ante el Fuero Contencioso Administrativo y Tributario de la Ciudad de Buenos Aires. El segundo, que es el que vamos a desarrollar y analizar particularmente, se suscitó cuando el gobierno porteño decidió mudar allí el Ministerio de Desarrollo Humano y Hábitat, lo que implicaba que las estructuras serían demolidas casi en su totalidad. Puede interpretarse, entonces, como un desplazamiento por la instalación de una 
Cravino, M.C. Justicia y política de hábitat en la Ciudad de Buenos Aires en desalojos de ocupaciones de suelo: Papa Francisco y Elefante Blanco. Derecho y Ciencias Sociales. Mayo- Octubre 2019 N $^{\circ} 21$. (Derecho, ciudad y propiedad) Pgs 104-129. ISNN 1852-2971. Instituto de Cultura Jurídica y Maestría en Sociología Jurídica. FCJ y S. UNLP

infraestructura estatal. ${ }^{21}$ Este caso, al igual que el anterior, pone en jaque algunas categorías que parecerían precisas, pero tienen numerosos grises: el edificio y las viviendas construidas en sus alrededores habían sido incorporados nominalmente a un sector de la villa 15 contigua y se la consideraba entonces como la manzana 27 bis. No era muy claro si desde las categorías nativas de los habitantes se trataba de una parte del barrio porque tenían fuertes diferencias: su constitución fue mucho más tardía y claramente era una zona diferenciada por su tipología (estructura en altura) y fundamentalmente porque no participaban de la organización territorial de la villa.

El Poder Ejecutivo de la Ciudad de Buenos Aires había decidido vaciarlo y derrumbarlo artesanalmente porque era imposible implosionarlo por haber viviendas muy cercanas. Para esto se propuso el desalojo compulsivo de sus habitantes, pero con la particularidad de "sacar familia por familia" y no todos de una vez. Esta decisión de entregar subsidios habitacionales para la ejecución de este desahucio, creemos, se dio porque una jueza ${ }^{22}$ del Fuero Contencioso Administrativo y Tributario porteño había ordenado mejorar las condiciones de salubridad, buscando frenar los desalojos compulsivos de aquellas familias, pero no su relocalización. Cabe aclarar que los subsidios no son similares a los que se otorga a personas en situación de calle (que se ofrecieron a los desalojados del Papa Francisco si lo solicitaban y se estudiaba caso a caso) sino que se trata de un monto que supuestamente alcanzaría para comprar una vivienda (por el precio en la villa o en la periferia). Luego, analizaremos la complejidad que implica distinguir conceptualmente y categorialmente desalojo de relocalización.

Esta judicialización contiene aspectos contradictorios: por un lado, constituyó un caso de activismo judicial por las condiciones de vida de sus habitantes y donde el Ministerio Público de la Defensa tuvo un rol central. En particular, se utilizó la innovadora figura del amparo colectivo (Gustavo Elías Serra c/gobierno de la Ciudad de Buenos Aires s/amparo). Por otro, tuvo un alcance limitado y ante el incumplimiento de las mandas judiciales (Dos Santos Freire y Ruiz Conti, 2016), este poder no pudo garantizarlas y se evidenció una lenta retirada del caso que permitió y, en cierta medida, convalidó el desalojo. Estos reclamos tuvieron antecedentes por parte de la Defensoría del Pueblo de la Ciudad y del Ministerio Público Tutelar, que en años previos realizaron consultas a diferentes organismos del gobierno local ante la crítica

\footnotetext{
${ }^{21}$ Más aún, cuando un informante del Poder Judicial del distrito indicó que, según un estudio de una urbanista francesa, que consideraba serio, afirmaba que el edificio era $100 \%$ recuperable y podía reciclarse como vivienda de interés social. No obstante, para el gobierno local el edificio fue siempre considerado irrecuperable.

${ }^{22}$ Elena Liberatori.
} 
Cravino, M.C. Justicia y política de hábitat en la Ciudad de Buenos Aires en desalojos de ocupaciones de suelo: Papa Francisco y Elefante Blanco. Derecho y Ciencias Sociales. Mayo- Octubre 2019 N $^{\circ} 21$. (Derecho, ciudad y propiedad) Pgs 104-129. ISNN 1852-2971. Instituto de Cultura Jurídica y Maestría en Sociología Jurídica. FCJ y S. UNLP

situación del edificio, que otorgó respuestas ambiguas o evasivas y por lo que se les solicitó que confeccionaran un plan integral.

El tratamiento de la causa judicial tramitada en el Fuero Contencioso Administrativo y Tributario tuvo las características del ciclo de activismo judicial (Delamata, 2014; Cravino, 2016). En particular, por dos aspectos. Por un lado, por el acercamiento de personal del juzgado (incluida la jueza) al territorio y por la realización de audiencias donde algunos de los vecinos pudieron exponer su situación. No obstante, ya en una etapa de declive de dicho activismo, fue evidente que la voz de los ocupantes no fue totalmente escuchada y menos incorporado su punto de vista. En paralelo, como evidencia del debilitamiento citado, tampoco se pudo garantizar su cumplimiento. Un entrevistado del Poder Judicial relataba que ellos iban a verificar, pero que siempre encontraban faltas a la manda de la jueza.

El segundo momento puede ser denominado "desalojo silencioso". El adjetivo alude a que el gobierno local buscaba que las expulsiones coercitivas fueran presentadas como realojo humanitario, es decir asistencial. Esto se reflejó en el modo de abordar el tema en la prensa, la que no los denominaba a los habitantes como usurpadores, tal como se hizo en el caso del Parque Indoamericano (Cravino, 2014; Fava, 2014) o en Papa Francisco, sino más bien como víctimas de sufrimiento ambiental.

De este modo, en las notas periodísticas se resaltó las dramáticas condiciones de vida que tenían y se legitimaba su realojo. Se dejaban atrás proyectos previos de construir viviendas de interés social en ese predio, los que ya estaban acordados. La justicia hizo caso omiso de estos antecedentes. Para esto fue fundamental que la jueza considerara que ese lugar era inhabitable y no ensayara otras posibilidades como el reciclado del edificio o la entrega de viviendas terminadas por parte del Gobierno de la Ciudad en otro lugar. Eso llevó a que el dispositivo elegido por el Estado local fuera la solución vía subsidio a cada familia, convirtiendo a la estrategia de la Defensoría General de la Ciudad a un mero acompañamiento, si era posible, en ese trámite.

No obstante, el mecanismo que utilizaba el Gobierno de la Ciudad de Buenos Aires ${ }^{23}$ era visitar a las familias y amedrentarlas, ya que técnicos del Ministerio de Desarrollo Humano y Hábitat les decían que debían retirarse del predio y que resultaría inminente un desalojo de su

\footnotetext{
${ }^{23}$ Un mecanismo similar había sido utilizado por la gestión local del mismo partido político entre 2011-2015, para el caso de viviendas sociales de una zona de patrimonio arquitectónico, La Manzana de las Luces, donde la Ministra de Desarrollo Social (María Eugenia Vidal), actuaba en paralelo al pedido de la Defensoría General de la Ciudad, otorgando subsidios para personas en situación de calle, que sólo alcanzaban para pagar una pieza en un hotel pensión. En este caso, el agravante era que desde la década de 1990 estas personas tenían contrato de alquiler con el gobierno local.
} 
Cravino, M.C. Justicia y política de hábitat en la Ciudad de Buenos Aires en desalojos de ocupaciones de suelo: Papa Francisco y Elefante Blanco. Derecho y Ciencias Sociales. Mayo- Octubre 2019 N $^{\circ} 21$. (Derecho, ciudad y propiedad) Pgs 104-129. ISNN 1852-2971. Instituto de Cultura Jurídica y Maestría en Sociología Jurídica. FCJ y S. UNLP

vivienda sin ningún tipo de consideración si no aceptaban el trato que se les ofrecía. Esto coincide con los testimonios recabados por Duacastella (2016), que indican que las familias eran citadas de forma individual y se "negociaba" con ellas un subsidio habitacional que venía acompañado de la amenaza de que si no aceptaban iban a demoler sus viviendas con sus pertenencias adentro.

El modo en que se sucedieron estos procesos fue altamente irregular: les requerían que personas conocidas se presentaran como si estuvieran viviendo con ellos, así también podían cobrar el subsidio de aquellas y se abultaba entonces el monto que recibían. En este caso no encontramos la elaboración de un discurso de derechos en los reclamos de los habitantes, explicado en parte, por la incapacidad para conformar una organización, coadyuvado por su condición de amenazados. Inclusive, en esa tarea no sólo estaban involucrados técnicos del gobierno local, sino que también se sumaba la participación de un dirigente territorial de la Villa 15 con antecedentes de prácticas violentas como emisor de la amenaza estatal extra oficial.

Muchos de los ocupantes querían permanecer en el lugar a pesar de las deplorables condiciones, pero otros no. Entre estos últimos se encontraban los que habitaban dentro de la estructura edilicia que estaban dispuestos a irse debido a la basura acumulada, los sótanos con líquidos cloacales y los vectores trasmisores de enfermedades como ratas, moscas y mosquitos. A esto se sumaban algunos problemas edilicios, como por ejemplo la caída de mampostería del edificio. Eso los diferenciaba de los habitantes de Papa Francisco que lucharon cohesionadamente por permanecer. Un agravante del desalojo se desprende de una descripción del diario La Nación: "Cuando una familia logra reubicarse, la casa se derrumba. No se limpia ni se acomoda el terreno" (La Nación, Buenos Aires, 14 de febrero de 2018). Esto tenía que ver con evitar el costo de una custodia y quizás un fin disciplinante. En esa nota, también, se describía que la mayor cantidad de escombros provocaba mayor presencia de roedores y hasta se relataba una niña jugando con una jeringa tomada de la pila de la basura. La prensa hegemónica nunca mencionaba, por su parte, la palabra "desalojo", sino reubicación.

Las personas que habían vivido en el edificio que pudimos contactar no accedieron a ningún tipo de acompañamiento legal de la Defensoría General de la Ciudad, la que sólo logró contactar a algunos habitantes. De este modo, se daba una situación paradójica: ese organismo de la defensa buscaba a los habitantes para proteger sus derechos, pero ellos eran desalojados uno a uno bajo amenazas. Esto puede ser entendido como una puja intraestatal, donde se evidencia la desigualdad del poder de los organismos. También puede interpretarse como una 
Cravino, M.C. Justicia y política de hábitat en la Ciudad de Buenos Aires en desalojos de ocupaciones de suelo: Papa Francisco y Elefante Blanco. Derecho y Ciencias Sociales. Mayo- Octubre 2019 N $^{\circ} 21$. (Derecho, ciudad y propiedad) Pgs 104-129. ISNN 1852-2971. Instituto de Cultura Jurídica y Maestría en Sociología Jurídica. FCJ y S. UNLP

pérdida lenta, pero constante de la capacidad de incidencia de la agencia judicial, que quizás también sufriera un proceso de "domesticación”, es decir una pérdida de su intención de litigar con el Gobierno de la Ciudad de Buenos Aires. Arcidiácono y Gamallo (2017) se refieren a la autolimitación del Poder Judicial en los pleitos por acceso a un subsidio habitacional para personas en situación de calle, lo que iría en el mismo sentido que lo que planteamos para el caso que estamos analizando.

En otras palabras, el Poder Judicial, juega el juego del Poder Ejecutivo, apenas corriendo un poco su alcance. Esto tiene como consecuencia un no cuestionamiento de las políticas públicas como una de las dimensiones políticas y simbólicas. La idea de cómo debe ser el control o contrapeso de este poder en relación al ejecutivo es uno de los interrogantes que se abren cuando los gobiernos (en este caso el de la Ciudad de Buenos Aires) no garantiza el derecho a una vivienda adecuada e incluso viola el derecho al acceso a la información, a la participación y la ecuanimidad.

Entonces, de acuerdo a la capacidad de presión de las familias e inclusive el orden de las expulsiones (los últimos recibieron más dinero), los acuerdos fueron diferentes y totalmente discrecionales. Complementariamente, y con la estrategia de impedir formas organizativas entre los ocupantes, todos coinciden en relatar en que aquellos que tuvieron algún rol de representación recibieron más dinero y fueron resueltos con prioridad. Esto tenía como fin desarticular rápidamente cualquier intento de organización, que de por sí era débil. Además, los entrevistados tenían fuertes sospechas de que los funcionarios de gobierno se habían quedado con parte de sus subsidios.

Estas dificultades para plantear resistencia o mejores condiciones al desalojo en este caso se vinculan, además del débil acompañamiento de los organismos de la defensa, a que, a diferencia del anterior, los habitantes del edificio sólo tuvieron asesoramiento personal de personas de la villa 15 que participaban de organizaciones barriales y al comienzo de miembros de la Fundación Madres de Plaza de Mayo. No obstante, este acompañamiento no dejó de ser de organizaciones que se encontraban presentes en la villa, no más allá de ella.

\section{El Estado y los modos de desalojo}

En Argentina, décadas atrás, cuando una tierra ocupada por personas con necesidades habitacionales era fiscal la tolerancia a su permanencia en el lugar era mayor a que si era 
Cravino, M.C. Justicia y política de hábitat en la Ciudad de Buenos Aires en desalojos de ocupaciones de suelo: Papa Francisco y Elefante Blanco. Derecho y Ciencias Sociales. Mayo- Octubre 2019 N $^{\circ} 21$. (Derecho, ciudad y propiedad) Pgs 104-129. ISNN 1852-2971. Instituto de Cultura Jurídica y Maestría en Sociología Jurídica. FCJ y S. UNLP

privada. ${ }^{24}$ Se podía presuponer instancias de negociación política sobre su consolidación o traslado, aunque ya eran recurrentes los conflictos y cierta resistencia del Estado a aceptar la conformación de un barrio popular. En cambio, cuando se trataba de suelo privado, dependía de la decisión del dueño del predio de impulsar el procedimiento de desalojo o iniciar procesos de venta directa a los ocupantes. La expropiación (o el canje de tierras) era (y es) una opción del Estado a fin de resolver el conflicto entre privados, el que nunca es estrictamente tal, ya que siempre conlleva una cuestión pública.

En el caso de la Ciudad de Buenos Aires, desde la asunción del partido político Propuesta Republicana (PRO) en el año 2007 y luego en alianza con otros partidos políticos, dando lugar al nombre Cambiemos, estos arreglos políticos fueron dejando de suceder y hubo numerosos desalojos de pequeños asentamientos. Quedó marcada como regla de acción lo que se realizó para la toma del Parque Indoamericano en diciembre de 2010: desalojo violento si hubiera resistencia por parte de los pobladores.

En el caso de lo que luego se llamó la villa Papa Francisco, los que tomaron el predio lo hacían en nombre del derecho a la vivienda que no se cumplía, tal como lo establecía una ley de urbanización de la villa 20 (sancionada 7 años atrás). Este no fue un argumento público suficiente en un marco de oportunidades políticas muy estrecho y no pudo impedir el desalojo o establecer un realojo negociado. En el caso del Elefante Blanco, el Estado local nunca buscó la alternativa de resolver la radicación de los ocupantes en ese predio y la intervención frente a las condiciones ambientales desfavorables pasó a ser sólo una medida transitoria, a fin de cumplir mandatos judiciales, pero con el objetivo firme de proceder al desalojo.

Al tener el Poder Judicial distintos organismos se suceden disputas por el monopolio de fijar qué es el derecho (Bourdieu, 2000) en los casos de ocupaciones de suelo, que presentan aristas sociales y políticas complejas. Los operadores jurídicos realizaron un "trabajo" de actualización de las normas (Azuela, 2014), donde la institución de la propiedad, en este caso estatal, fue reafirmada como absoluta en función de los intereses del Poder Ejecutivo local. Esto se estableció en detrimento de las necesidades y derechos de los habitantes de la villa Papa Francisco y el edificio del Elefante Blanco. Las personas que ocuparon suelo urbano en los dos casos analizados eran conscientes que eludían la ley vigente, pero contraponían prácticas que

\footnotetext{
${ }^{24}$ Esa tendencia, que surge de la observación de los casos conocidos en el AMBA desde la década de 1900, fue revertida por el accionar del gobierno de la Ciudad de Buenos Aires desde 2007 en adelante. Esta cuestión merecería un estudio en profundidad a futuro.
} 
Cravino, M.C. Justicia y política de hábitat en la Ciudad de Buenos Aires en desalojos de ocupaciones de suelo: Papa Francisco y Elefante Blanco. Derecho y Ciencias Sociales. Mayo- Octubre 2019 N $^{\circ} 21$. (Derecho, ciudad y propiedad) Pgs 104-129. ISNN 1852-2971. Instituto de Cultura Jurídica y Maestría en Sociología Jurídica. FCJ y S. UNLP

consideraban legítimas a normas legales. No creían que hacían un daño, ya que se justificaban en su necesidad de obtener un lugar donde establecerse en la ciudad.

El rol del Poder Judicial en estos conflictos contribuyó a fijar límites más duros a las prácticas arraigadas en la vida urbana de los sectores populares, que resolvían sus necesidades ocupando suelo abandonado. Está claro que el Poder Judicial no se ocupa de las cuestiones de fondo (Arcidiácono y Gamallo, 2017) del acceso al suelo urbano y a la vivienda porque no está en su naturaleza, sino que esto último corresponde al Poder Ejecutivo. En los casos analizados lo hizo de dos modos diferentes: en uno con violencia estatal represiva y, en el otro, con subsidios habitacionales insuficientes para resolver el tema para las familias y en procesos plagados de irregularidades.

Las razones de la diferencia en la modalidad de acción del Gobierno de la Ciudad de Buenos Aires, creemos que se explica por dos razones:

En primer lugar, tiene que ver con los antecedentes previos en cada caso en el modo de ocupación. En el Elefante Blanco, los primeros ocupantes ya habían sido legitimados, de algún modo, por el Estado en carácter de "cuidadores" informales o acreditaban cierta antigüedad (Cravino y González Carvajal, 2012). El espacio estaba a las sombras del Estado y adquirió visibilidad cuando el gobierno local tuvo interés en instalar allí un ministerio. Y no menos importante era que la Defensoría General de la Ciudad había interpuesto medidas cautelares para que fuera saneado el lugar y, por lo tanto, el Poder Ejecutivo porteño estaba en una situación de exposición por parte de un organismo público de defensa de derechos sociales. No obstante, eso no impidió que se recurriera el desahucio, pero para gestionarlo se utilizaron compensaciones monetarias. Entonces, el desalojo fue justificado por dos motivos: la primera por supuestas razones humanitarias y la segunda, por la necesidad de utilizar el predio para un fin institucional de relevancia. En el caso de la villa Papa Francisco, originalmente se trataba de un espacio abandonado, pero que generaba daño ambiental a la villa contigua (villa 20 de Lugano), ya que allí se habían depositado automóviles. Fue necesaria la intervención de la Justicia (por medio del Fuero Contencioso Administrativo y Tributario) para que se retiraran aquellos, aunque nunca se había logrado el saneamiento completo. En estas condiciones fue ocupado el predio y en un contexto donde el gobierno local había decidido tolerancia cero a las nuevas ocupaciones, el desalojo estaba decidido desde el primer día. Eso permitió que el Estado local se presentara como actuando ante un hecho novedoso, aunque había sido tolerante de modo pasivo a la expansión de la Villa 20 hacia el sector que luego fuera tomado. 
Cravino, M.C. Justicia y política de hábitat en la Ciudad de Buenos Aires en desalojos de ocupaciones de suelo: Papa Francisco y Elefante Blanco. Derecho y Ciencias Sociales. Mayo- Octubre 2019 N $^{\circ} 21$. (Derecho, ciudad y propiedad) Pgs 104-129. ISNN 1852-2971. Instituto de Cultura Jurídica y Maestría en Sociología Jurídica. FCJ y S. UNLP

La segunda razón se vincula a procesos de carácter simbólico-político. En el caso del Papa Francisco se desplegó un discurso muy fuerte por parte del gobierno local en relación a su deslegitimación pública, presentando a los ocupantes como delincuentes y vinculándolos al narcotráfico. En cambio, el discurso de dicho gobierno en el caso del Elefante Blanco fue de reparación de una situación crítica socio-ambientalmente y presentando, entonces, como víctimas a los ocupantes del Elefante blanco. Para un caso la respuesta era el desalojo y para el otro, la relocalización. Sin embargo, en ambos fueron expulsados los pobladores, pero de diferente modo: en uno con violencia y en otro con subsidios habitacionales. Es relevante tener presente que ese subsidio no estaba ajustado a sus necesidades de vivienda sino a acciones discrecionales de los funcionarios del Gobierno de la Ciudad de Buenos Aires, pero le otorgaban un halo de negociación a lo que fue un proceso compulsivo. En el primer caso, cuando permanecía en el tiempo y no lograban el desalojo también sumaron la idea de sufrimiento ambiental (Auyero y Swistun, 2007), para darle mayor legitimidad, aunque esto entraba en contradicción con el modo violento del desahucio.

\section{Reflexiones finales}

Nos proponemos aquí recuperar dos ejes de análisis para concluir la interpretación de los casos estudiados: a) judicialización de la política y de los conflictos de acceso al suelo y b) desalojos de ocupaciones de suelo desde la dimensión socio-política y simbólica.

En relación a la judicialización de la política (Smulovitz, 2008), y específicamente a la judicialización de los conflictos de acceso al suelo, encontramos diferencias en relación a los dos casos. Nosetto (2014), retomando a Sieder, Schjolden y Angell (2008) plantea que la judicialización de la política puede clasificarse como: a) desde abajo, es decir por actores de la sociedad civil; y b) desde arriba, cuando es generada por las elites políticas y judiciales. En el conflicto por el barrio Papa Francisco la solicitud de intervención judicial partió desde el Gobierno de la Ciudad de Buenos Aires y las respuestas dentro de los tribunales fueron ensayadas por diferentes actores que no lograron revertir la orden de desalojo. Se negaron instancias de negociación política como solía suceder en conflictos de este tipo (hasta antes del caso del Parque Indoamericano). En cuanto al Elefante Blanco observamos un doble proceso, ya que, por un lado, se inició con el acercamiento de los vecinos a una oficina descentralizada del Ministerio Público de la Defensa, pero éste fue quien interpuso un amparo colectivo. De ese modo, actores "de abajo" y "arriba" realizaron una alianza para que su espacio urbano se dirimiera en instancias judiciales. Paradójicamente, el desalojo se produce por parte del 
Cravino, M.C. Justicia y política de hábitat en la Ciudad de Buenos Aires en desalojos de ocupaciones de suelo: Papa Francisco y Elefante Blanco. Derecho y Ciencias Sociales. Mayo- Octubre 2019 N $^{\circ} 21$. (Derecho, ciudad y propiedad) Pgs 104-129. ISNN 1852-2971. Instituto de Cultura Jurídica y Maestría en Sociología Jurídica. FCJ y S. UNLP

Gobierno de la Ciudad sin medidas judiciales, mediante acciones que formalmente podrían denominarse "negociaciones individuales con las familias", pero que en un análisis sustantivo se traducirían en presiones para su expulsión.

De esto se desprende que el contexto y la coyuntura tienen fuerte peso en la decisión de la estrategia del Gobierno de la Ciudad de Buenos Aires ante conflictos por ocupación de suelo urbano. En los asentamientos más consolidados se ha optado en los últimos años por políticas de urbanización, pero hay excepciones como el caso del Elefante Blanco. Ese tratamiento diferencial puede ser comprendido también por la falta de reconocimiento de ese predio como un sector de un barrio, convirtiendo a ese espacio en un hiato urbano-social sin una categoría clara de clasificación. En el caso de la villa Papa Francisco se aplicó el criterio que cobró relevancia con posterioridad a la toma del Parque Indoamericano, en relación a fijar un límite político a nuevas ocupaciones: tolerancia cero y desalojo. Para este fin, sin duda, se apeló a los tribunales.

En segundo lugar, creemos que en las prácticas analizadas también se dirime una disputa simbólico-política. Es central para esa dimensión la retórica, que implica detenernos en el lenguaje utilizado por los actores en el conflicto. En primer lugar, en que en un caso se busca utilizar desalojo y, en otros, realojo. De esta manera, más allá de las diferencias, consideramos que en los dos casos se trató de desalojos. El modo es lo que los diferencia, pero no el efecto. En un caso se efectuó por medio de engaños y represión policial y, en otro, acudiendo a subsidios habitacionales poco transparentes e insuficientes para resolver el acceso a una vivienda adecuada. Si bien, para el caso Elefante Blanco la jueza del Fuero Contencioso Administrativo y Tributario convalidó "relocalizaciones" por las condiciones sanitarias y ambientales del edificio, no se trató de tales, porque no fueron entregadas a cambio viviendas en buenas condiciones edilicias y urbanas. El uso de los términos no es neutro y utilizar "relocalización" permite ocultar la precaria respuesta del gobierno local a la falta de un techo digno por parte de los ocupantes del Elefante Blanco. En el caso de la villa Papa Francisco el desalojo se expone con visibilidad, justamente, para mostrar el límite político y jurídico en relación a las ocupaciones de suelo en la Ciudad de Buenos Aires.

Natalia Verón, en su estudio sobre desalojos de viviendas ocupadas, donde muestra el aval y rol activo del Estado local en la Ciudad de Buenos Aires, después del 2008, señala que la práctica estatal en estos casos, configura una asistencia ajena al reconocimiento de un derecho vulnerado, el de la vivienda. Afirma que "en diversos momentos el lenguaje estatal penduló entre un modelo basado en la negociación como instancia legitimadora del desalojo a otro de 
Cravino, M.C. Justicia y política de hábitat en la Ciudad de Buenos Aires en desalojos de ocupaciones de suelo: Papa Francisco y Elefante Blanco. Derecho y Ciencias Sociales. Mayo- Octubre 2019 N $^{\circ} 21$. (Derecho, ciudad y propiedad) Pgs 104-129. ISNN 1852-2971. Instituto de Cultura Jurídica y Maestría en Sociología Jurídica. FCJ y S. UNLP

corte disciplinar tutelado" (Verón, 2013: 193). Este modelo no se puede aplicar a la villa Papa Francisco ya que allí la respuesta fue la violencia. En cambio, en el caso del Elefante Blanco tendría algunas similitudes por tratarse de un edificio ocupado, pero al carecer de organizaciones, el gobierno local optó directamente por un mecanismo disciplinador tutelado. Y en contraste el Poder Judicial legitimó esa expulsión administrativa.

Queda señalar que ese efecto pedagógico de los desalojos nunca es completo cuando las necesidades de un lugar en la ciudad para diversos grupos de vecinos continúan intactas y el fondo de la controversia no se resuelve. Por su parte, en los operadores jurídicos se hacen presentes disposiciones, saberes, miradas que no provienen del campo judicial, sino del campo social en el que están insertos (Arenaza y Fava, 2013). Por ello, para entender sus fallos se requiere comprender el contexto socio-político, la tematización de la cuestión en la esfera pública y las concepciones de orden social que sostienen los operadores jurídicos. A esto se agrega, que en la Ciudad de Buenos Aires fue explícita la puja de poderes, en particular entre el Poder Ejecutivo y el Judicial, pero también entre fueros de este último poder y fiscalías y organismos de defensa. Muestra, entonces, que las situaciones analizadas fueron leídas en su carácter político por el Poder Ejecutivo local y la Justicia acompañó esta lectura coyuntural y donde los organismos de la defensa fueron débiles en su rol.

Tanto en el caso de desahucios de viviendas ocupadas colectivamente como de asentamientos informales recientes o edificios abandonados, la estrategia política fue común: no reconocer derechos y sólo en algunos casos acudir a subsidios con carácter de emergencia. Pero para recibir estos subsidios había que cumplir un trámite que implicaba reconocerlos como merecedores de la asistencia. En el caso del Papa Francisco, aun cuando los habitantes contaban con seis meses de permanencia, les fue negada esta asistencia porque fueron considerados okupas e ilegales.

Como síntesis, podemos afirmar que se da un doble proceso: cuando la negociación política fracasa se pasa a la judicialización, pero esta última no significa circunscribir el conflicto del desalojo en este ámbito, sino que lo desborda y este mismo no se termina de traducir completamente en términos jurídicos, sino que se mantiene politizado. En nuestros casos vemos entonces que un conflicto socio urbano como la villa Papa Francisco es "resuelto" en parte por la Justicia Penal con un desalojo, pero este no "resuelve" el problema social de quienes se quedan sin vivienda. Por lo tanto, la justicia no puede dejar de estar atravesada por la política en un contexto donde la política elige como estrategia la judicialización. En el caso del Elefante Blanco, la justicia solo "soluciona" provisoriamente las condiciones ambientales degradadas, 
Cravino, M.C. Justicia y política de hábitat en la Ciudad de Buenos Aires en desalojos de ocupaciones de suelo: Papa Francisco y Elefante Blanco. Derecho y Ciencias Sociales. Mayo- Octubre 2019 N $^{\circ} 21$. (Derecho, ciudad y propiedad) Pgs 104-129. ISNN 1852-2971. Instituto de Cultura Jurídica y Maestría en Sociología Jurídica. FCJ y S. UNLP

pero queda ajena a la resolución del acceso a la vivienda, donde sólo convalida arreglos de hecho, desfavorables para sus habitantes. Por último, cabe señalar que en ambos casos, las decisiones estatales, tanto del Poder Judicial como del Ejecutivo, implicaron la violación de derechos económicos, sociales, culturales y ambientales, establecidos por medio de pactos internacionales y con rango constitucional.

\section{Bibliografía}

Arcidiácono, P. y Gamallo, G. (2014). Entre la confrontación y la funcionalidad. Poder Ejecutivo y Poder Judicial en torno a la política habitacional de la Ciudad de Buenos Aires. POSTData, 19 (1), 193-225.

Arcidiácono, P. y Gamallo, G. (2017). Quince años de litigio habitacional en la Ciudad de Buenos Aires. De la "otra ventanilla" al "cierre del grifo", Papeles de Trabajo [en línea], 11 209-230.

Disponible

en:

https://ri.conicet.gov.ar/bitstream/handle/11336/76519/CONICET_Digital_Nro.02b64bc6-

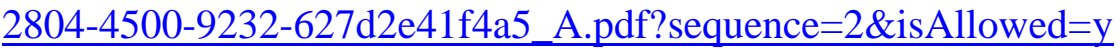

Arenaza, S. y Fava, R. (2013). Entre lo político y lo jurídico: arreglos institucionales en la justiciabilidad del derecho a la vivienda en la Provincia de Buenos Aires. En Abramovich, V., Arenaza, S., Cravino, M. C., Fava, R. La protección judicial de los derechos sociales en la Provincia de Buenos Aires (pp. 19-48). Lanús: Ediciones UNLa.

Auyero, J. y Swistun, D. (2007). Expuestos y confundidos. Un relato etnográfico sobre sufrimiento ambiental. Iconos. Revista de Ciencias Sociales [en línea], (28), 137-152. Disponible en: https://www.redalyc.org/pdf/509/50902812.pdf

Azuela, A. (2014). Introducción. Los juristas y las ciencias sociales frente al activismo judicial y los conflictos urbano-ambientales en América Latina. En: Azuela, A. y Cancino, M. Á. (Coords.) Jueces y conflictos urbanos en América Latina (pp. 7-33). México: PAOT-IRGLUS.

Bertoni, E. (2010) (comp.). ¿Es legítima la criminalización de la protesta social? Derecho penal y libertad de expresión en América Latina. Buenos Aires: Universidad de Palermo.

Bourdieu, P. (2000). Elementos para una sociología del campo jurídico. En: Bourdieu, P. y Teubner, G. La fuerza del derecho (pp.153-220). Bogotá: Uniandes. Bourdieu, P. (2001). Poder, Derecho y Clases Sociales. Bilbao: Descleé de Brouwer. 
Cravino, M.C. Justicia y política de hábitat en la Ciudad de Buenos Aires en desalojos de ocupaciones de suelo: Papa Francisco y Elefante Blanco. Derecho y Ciencias Sociales. Mayo- Octubre 2019 № 21. (Derecho, ciudad y propiedad) Pgs 104-129. ISNN 1852-2971. Instituto de Cultura Jurídica y Maestría en Sociología Jurídica. FCJ y S. UNLP

Carman, M. (2006). La invención de la etnicidad y el desalojo de ocupantes ilegales en el barrio del Abasto de Buenos Aires. Intersecciones en Antropología, (7). Olavarría.

CELS - Centro de Estudios Legales y Sociales (2017). El derecho a la protesta social en Argentina [en línea]. Buenos Aires: CELS. Disponible en: https://www.cels.org.ar/protestasocial/pdf/CELS_Protesta_Arg.pdf

Cravino, M. C. (2006). Las villas de la ciudad: mercado e informalidad urbana. Los Polvorines: UNGS.

Cravino, M. C. (2008). Entre el arraigo y el desalojo. Villa 31. Los Polvorines: UNGS.

Cravino, M. C. y González Carvajal, M. L. (2012). Criterios de asignación de viviendas y construcción de legitimidades en la implementación de programas de urbanización de asentamientos informales en el Gran Buenos Aires. Quid 16 [en línea], (2), 154-173. Disponible

en:

file:///C:/Users/cristina/Documents/PICT\%202017/DESALOJOS/cravino\%20gonzalez\%20carb ajal\%202012.pdf

Cravino, M. C. (2014) (Comp.) Derecho a la ciudad y conflictos urbanos. La ocupación del parque Indoamericano. Los Polvorines: UNGS.

Cravino, M.C. (2016). Poder judicial y ocupaciones de suelo en Buenos Aires. Direito e Praxis [en línea], 7(14), 454-491. Disponible en: $\underline{\text { https://www.e- }}$ publicacoes.uerj.br/index.php/revistaceaju/article/view/22953

Cravino, M. C. y Fainstein, C. (2017). Disputas por el acceso al ambiente sano y a la vivienda en la ribera del Riachuelo: derechos de los vecinos, acción de la justicia y políticas públicas. En: Cravino, M. C. (Coord.) Detrás de los conflictos. Estudios sobre desigualdad urbana en la Región Metropolitana de Buenos Aires (pp. 53-113). Los Polvorines: UNGS.

Delamata, G. (2014). Sectores populares, hábitat y derechos. En: Azuela, A. y Cancino, M. Á. (Coords.) Jueces y conflictos urbanos en América Latina (pp. 101-146). México: PAOTIRGLUS.

Duacastella, J. (2016). El conflicto en el Elefante Blanco desde la perspectiva de sus habitantes. Revista institucional de la Defensa Pública de la Ciudad Autónoma de Buenos Aires, año 6 (8), $161-174$. 
Cravino, M.C. Justicia y política de hábitat en la Ciudad de Buenos Aires en desalojos de ocupaciones de suelo: Papa Francisco y Elefante Blanco. Derecho y Ciencias Sociales. Mayo- Octubre 2019 N $^{\circ} 21$. (Derecho, ciudad y propiedad) Pgs 104-129. ISNN 1852-2971. Instituto de Cultura Jurídica y Maestría en Sociología Jurídica. FCJ y S. UNLP

Fava, R. (2014). La clase media, entre la historia y la cultura. Representaciones sobre los "vecinos" en el conflicto con los "ocupantes" durante la toma del Parque Indoamericano. En: Cravino, M. C. (Coord.) Derecho a la ciudad y conflictos urbanos. La ocupación del Parque Indoamericano (pp. 85-112). Los Polvorines: UNGS.

Ferreira, M.V. (2016). Un hospital para enfermar. El Elefante Blanco como símbolo del problema de la salud y la vivienda en Buenos Aires. Revista institucional de la Defensa Pública de la Ciudad Autónoma de Buenos Aires, año 6 (8), 21-42.

Manzano, V. y Moreno, L. (2011). Censar, demandar y acordar: demandas colectivas y políticas estatales en el Gran Buenos Aires. Pilquen [en línea], Año XIII (14), 133-143. Disponible en: file:///C:/Users/cristina/Documents/PICT\%202017/DESALOJOS/moreno\%20\%20manzano\%202011.pdf

Martínez, C. (2004). Juegos de reconocimiento del derecho al espacio urbano en la Ciudad de Buenos Aires. El caso de la política de radicación de villas. Revista Lavboratorio, 6, 26-31.

Munck, G. (1995). Algunos problemas conceptuales en el estudio de los movimientos sociales. Revista Mexicana de Sociología, 57 (3), 17-40.

Nosetto, L. (2014). Reflexiones teóricas sobre la judicialización de la política argentina. Documentos y Aportes en Administración Pública y Gestión Estatal [en línea], (23), 93-123. Disponible en: $\quad$ http://www.scielo.org.ar/scielo.php?script=sci_arttext\&pid=S185137272014000200004

Olejarczyk, R. (2013). La producción de los sujetos de la política: la utilización del censo en los programas federales de construcción de viviendas. VII Jornadas Santiago Wallace de Investigación en Antropología Social. Instituto de Ciencias Antropológicas. Facultad de Filosofía y Letras, UBA, Buenos Aires.

Oszlak, O. (1991). Merecer la ciudad. Buenos Aires: Humanitas.

Ruiz Conti, M. F. y Dos Santos Freire, R. (2016). Estado de situación de la causa "Serra Gustavo c/Gobierno de la Ciudad de Buenos Aires s/amparo (art. 14 Constitución de la CABA). El caso del "Elefante Blanco". Revista institucional de la Defensa Pública de la Ciudad Autónoma de Buenos Aires, año 6 (8), 15-20.

Sieder, R., Schjolden, L. y Angell, A. (2008). La judicialización de la política en América Latina. Bogotá: Universidad Externado de Colombia. 
Cravino, M.C. Justicia y política de hábitat en la Ciudad de Buenos Aires en desalojos de ocupaciones de suelo: Papa Francisco y Elefante Blanco. Derecho y Ciencias Sociales. Mayo- Octubre 2019 N $^{\circ} 21$. (Derecho, ciudad y propiedad) Pgs 104-129. ISNN 1852-2971. Instituto de Cultura Jurídica y Maestría en Sociología Jurídica. FCJ y S. UNLP

Smulovitz, C. (2008). La política por otros medios. Judicialización y movilización legal en la Argentina. Desarrollo Económico 48(190/191), 287-305.

Tufró, M., Brescia, F. y Píngaro Lefevre, C. (2017). Aguantamos contra el Estado, perdemos contra las bandas. Reflexiones sobre la circulación de violencias en tomas de tierras y asentamientos de la Región Metropolitana de Buenos Aires. Quid 16 [en línea], (6), 146-168. Disponible en: https://www.cels.org.ar/web/wp-content/uploads/2018/01/Tufro-BresciaPingaro.pdf

Verón, N. (2013). Desalojos en la ciudad de Buenos Aires: la producción de las categorías y los espacios de la asistencia habitacional. Quid 16 (3), 170-194. 